\title{
Characteristics of pain-related factors in subgroups based on central sensitivity syndromes and pain in musculoskeletal pain patients: a cluster analysis
}

\author{
Hayato Shigetoh ${ }^{1,2}$, Yoichi Tanaka ${ }^{1,3}$, Masayuki Koga ${ }^{1,4}$, \\ Michihiro Osumi ${ }^{5}$, and Shu Morioka ${ }^{1,5}$ \\ ${ }^{1}$ Department of Neurorehabilitation, Graduate school of Health Sciences, Kio University \\ ${ }^{2}$ Miura Internal Medicine Michiko Pediatrics Clinic \\ ${ }^{3}$ Nara Prefectural General Rehabilitation Center \\ ${ }^{4}$ Kyouwakai Hospital \\ ${ }^{5}$ Neurorehabilitation Research Center, Kio University
}

\begin{abstract}
Central sensitization (CS) and psychological factors are associated with pain intensity. However, it has remained unclear whether the effects of central sensitivity syndromes and cognitive/ emotional factors differ depending on the severity of pain and the pain quality. Our purposes were to perform subgrouping based on central sensitivity syndromes and pain intensity, and to clarify the difference in central sensitization syndrome and pain intensity between subgroups.

Fifty-nine patients with musculoskeletal pain were included in this crosssectional study. Pain intensity and psychological problems were assessed with Central sensitization inventory (CSI-9), Short-Form McGill Pain Questionnaire 2 (SFMPQ2), Hospital Anxiety and Depression Scale (HADS), Pain Catastrophizing Scale (PCS-4). The cluster analysis with a ward method was used to divide patients into subgroups based on central sensitization syndrome and pain intensity. In addition, Kruskal-Wallis test, multiple comparison (Bonferroni method), and Fisher's exact test were performed to compare clinical outcomes between subgroups. The level of significance was set at $5 \%$.

The cluster analysis classified into three subgroups. One subgroup of patients $(\mathrm{n}=11)$ was characterized by high level of central sensitivity syndromes, pain intensity and psychological problems. A second subgroup $(n=19)$ was characterized by low level of central sensitivity syndromes, moderate level of pain intensity, high level of psychological problems. The third subgroup $(n=29)$ was characterized by low level of central sensitivity syndromes, pain intensity and psychological problems. That is, one subgroup was mainly affected with central sensitivity syndromes, and another subgroup was affected psychological factors. These results indicated the differences in pain mechanism among subgroups.
\end{abstract}




\title{
筋骨格系疼痛患者の中枢性感作症候群と痛みに基づいたサブグループにおける 疼痛関連因子の特性：クラスター解析を用いて
}

\author{
重藤 隼人 $1,2 /$ 田中 陽一 $1,3 /$ 古賀 優之 $1,4 /$ 大住 倫弘 $5 /$ 森岡 周 1,5 \\ 1 畿央大学大学院 健康科学研究科 神経リハビリテーション学研究室 \\ 2 三浦内科みちこ小児科クリニック \\ 3 奈良県総合リハビリテーションセンター \\ 4 協和会病院 \\ 5 畿央大学ニューロリハビリテーション研究センター
}

\section{はじめに}

近年になって，様々な筋骨格系疼痛患者の痛 みは，中枢性感作によって増悪することが報告 されている2,9)。中枢性感作は，「通常もしくは 閾值以下の上行性刺激に対して, 中枢神経シス テムにおける侵害受容ニューロンの感受性が増 大していること」と定義されており ${ }^{10)}$, 痛みを 増悪させる因子の一つとされている。一方で, 器質的異常を伴わないにもかかわらず中枢性感 作と関連する症状として, 中枢性感作症候群が 定義されている 23)。その評価ツールとして, Central Sensitization Inventory (CSI) がよく用 いられている12)。なお本邦でも，CSI 日本語版 が開発され，その妥当性と信頼性が既に確認さ れている 15,17)。CSI スコアは，能力障害や痛み との関連が報告されており ${ }^{13,14,19)}$, 中枢性感作 症候群は痛みを増悪させる因子として注目され ている。
また，認知および情動的因子も中枢性感作症 候群と同様に痛みを増悪させる因子であること

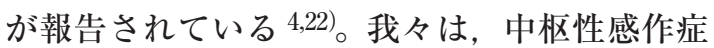
候群と認知および情動的因子がどのように痛み に影響しているか媒介分析を用いて検討し，認 知および情動的因子は中枢性感作症候群を介し て痛みを増悪させることを明らかにした ${ }^{16) 。 し ~}$ かし, 痛みと中枢性感作症候群㧍よび認知的因 子の関連は認めたものの, 痛みの重症度によっ ては, 中枢性感作症候群および認知・情動的因 子が複合的に影響している可能性がある。しか しながら，このことについては明らかにされて いない。加えて, 中枢性感作症候群と認知 ・情 動的因子が痛みの性質へ与える影響についても 明らかにされていない。

そこで我々は，認知・情動的因子によって痛 みが増悪するグループ, 中枢性感作症候群に よって痛みが増悪するグループ，これらの要因 全てが関与して痛みが増悪するグループなど, 


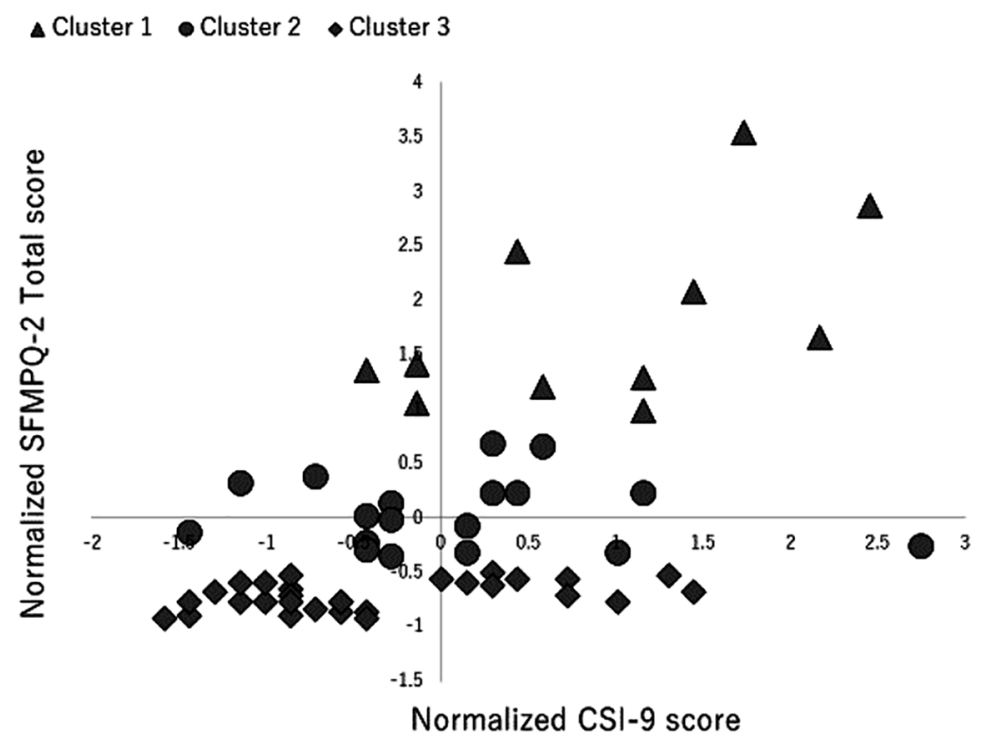

Fig.1 The scatter plot of SFMPQ-2 Total score and CSI-9 score each cluster.

This scatter plot showed standardized the CSI-9 score and SFMPQ-2 total score, and classified into clusters.

様々なサブグループが存在し，さらには，それ らの要因が特異的に与える痛みの性質があるの ではないかと仮説を立てた。よって本研究の目 的は, 中枢性感作症候群と痛みのスコアに基づ いて疼痛有訴者をサブグループに分類し，サブ グループごとの臨床的特徴を明らかにすること である。

\section{方 法}

\section{1. 対象者}

対象者は，多施設における入院患者および外 来患者 59 例とした（男性 16 例，平均年齢 $71.4 \pm 10.3$ 歳)。取り込み基準は, 疼痛有訴者と し, 疾患内訳は, 頸椎症 4 名, 頸椎捻挫 1 名, 脊椎手術後 5 名, 脊椎圧迫骨折 2 名, 脊柱管狭 管症 1 名, 変形性腰椎症 14 名, 大腿骨骨折術 後 8 名, 膝蓋骨骨折 1 名, 人工股関節術後 3 名,
人工膝関節術後 2 名, 変形性膝関節症 12 名, 肩関節周囲炎 5 名, 廃用症候群 1 名であった。 除外基準は, 質問紙への回答および理解が困難 な者とした。本研究は畿央大学倫理委員会 (承 認番号：H30-06）の承認を得ており, 対象者に は口頭にて説明し，同意を得ている。

\section{2. 調査項目}

中枢性感作症候群の評価には, Central Sensitization Inventory (CSI) -9 を使用した ${ }^{15)}$ 。 CSI-9 のカットオフ值である 20 点以上の対象者 の人数も算出した ${ }^{18)}$ 。痛みの評価には, Shortform McGill Pain Questionnaire-2 (SFMPQ-2) ${ }^{11)}$ を使用し，その合計点に加え，下位項目である 持続痛, 間欠痛, 感情表現, 神経障害性疼痛の 各項目の合計点も算出した。疼痛については, 主要な疼痛部位を確認し, 疼痛部位数と疼痛罹 患期間についても聴取した。また認知・情動因 子の評価には, 不安・抑うつの評価に Hospital 
Table 1 Characteristics of each variable each cluster

\begin{tabular}{|c|c|c|c|c|}
\hline Variables & $\begin{array}{c}\text { Cluster } 1 \\
(\mathrm{n}=11)\end{array}$ & $\begin{array}{c}\text { Cluster } 2 \\
(\mathrm{n}=19)\end{array}$ & $\begin{array}{c}\text { Cluster } 3 \\
(\mathrm{n}=29)\end{array}$ & $P$ value \\
\hline Age & $67.2 \pm 20.7$ & $71.7 \pm 11.2$ & $71.4 \pm 10.3$ & N.S. \\
\hline Gender (Male : Female) & $1: 10$ & $8: 11$ & $7: 22$ & N.S. \\
\hline \multirow{4}{*}{ Main painful area } & Neck 2 & Neck 1 & Neck 1 & \multirow{4}{*}{ N.S. } \\
\hline & Low back 3 & Low back 7 & Low back 11 & \\
\hline & $\mathrm{U} / \mathrm{E} 1$ & $\mathrm{U} / \mathrm{E} 2$ & $\mathrm{U} / \mathrm{E} 3$ & \\
\hline & $\mathrm{L} / \mathrm{E} 5$ & $\mathrm{~L} / \mathrm{E} 9$ & $\mathrm{~L} / \mathrm{E} 14$ & \\
\hline Number of pain sites & $2.1 \pm 0.7$ & $2.0 \pm 1.0$ & $1.6 \pm 0.6$ & N.S. \\
\hline Pain duration (month) & $35.7 \pm 57.7$ & $28.2 \pm 40.2$ & $16.9 \pm 29.8$ & N.S. \\
\hline CSI-9 & $18.5 \pm 6.4$ & $12.5 \pm 6.2$ & $9.3 \pm 5.8$ & $\mathrm{p}<0.01$ \\
\hline Numbers of more than CSI-9 cut off score $\geqq 20(\%)$ & $6(54.5 \%)$ & $2(10.5 \%)$ & $2(6.9 \%)$ & $\mathrm{p}<0.01$ \\
\hline SFMPQ-2 Total score & $93.0 \pm 26.0$ & $34.9 \pm 10.2$ & $10.0 \pm 4.2$ & $\mathrm{p}<0.01$ \\
\hline Continuous pain & $28.5 \pm 10.7$ & $13.4 \pm 5.8$ & $4.8 \pm 2.9$ & $\mathrm{p}<0.01$ \\
\hline Intermittent pain & $23.8 \pm 15.7$ & $9.5 \pm 5.2$ & $2.1 \pm 2.8$ & $\mathrm{p}<0.01$ \\
\hline Affective descriptors & $18.5 \pm 10.9$ & $3.7 \pm 3.5$ & $1.0 \pm 2.3$ & $\mathrm{p}<0.01$ \\
\hline Neuropathic pain & $22.2 \pm 8.9$ & $8.4 \pm 3.8$ & $2.1 \pm 2.6$ & $\mathrm{p}<0.01$ \\
\hline HADS & $16.5 \pm 8.1$ & $11.6 \pm 4.2$ & $8.0 \pm 5.4$ & $\mathrm{p}<0.01$ \\
\hline PCS-4 & $9.8 \pm 3.0$ & $9.3 \pm 3.6$ & $6.4 \pm 3.7$ & $\mathrm{p}<0.01$ \\
\hline
\end{tabular}

Average $\pm \mathrm{SD}$

P value showed the result of Kruskal-Wallis test, and Fisher's exact test (gender, main painful area, numbers of more than CSI-9 cut off score $\geqq 20$ ).

CSI-9, central sensitization inventory-9; SFMPQ-2, Short-Form McGill Pain Questionnaire-2; HADS, hospital anxiety and depression Scale; PCS-4, pain catastrophizing scale-4; U/E, Upper Extremity; L/E, Lower Extremity, N.S., not significant.

Anxiety and Depression Scale (HADS) 7), 破局 的思考の評価に Pain Catastrophizing Scale (PCS) $-4^{3)}$ を用いた。

\section{3. 統計解析}

まずは SFMPQ-2 合計值と CSI-9 スコアを用 いたクラスター解析 (Ward 法) によって, 対象 者をいくつかのサブグループに分類した。その 後に, 各クラスターにおける CSI-9 スコアと SFMPQ-2 合計值を標準化処理（Zスコア）し, 散布図を用いて視覚的にクラスター間で比較し た。また，各クラスターの各変数を比較するた め Kruskal-Wallis 検定および多重比較
（Bonferroni 法）を行った。性別, 主要な疼痛 部位, CSI-9 スコアのカットオフ基準該当者数 については，Fisher の直接確率法を用いて各ク ラスター間で比較した。有意水準は $5 \%$ とした。 統計解析には R version 3.6.1 を使用した。

\section{結 果}

\section{1. 痛みと中枢性感作症候群に基づいた クラスター解析}

標準化（Zスコア）したCSI-9スコアと SFMPQ-2 合計值の散布図を Fig.1 に示す。ク 

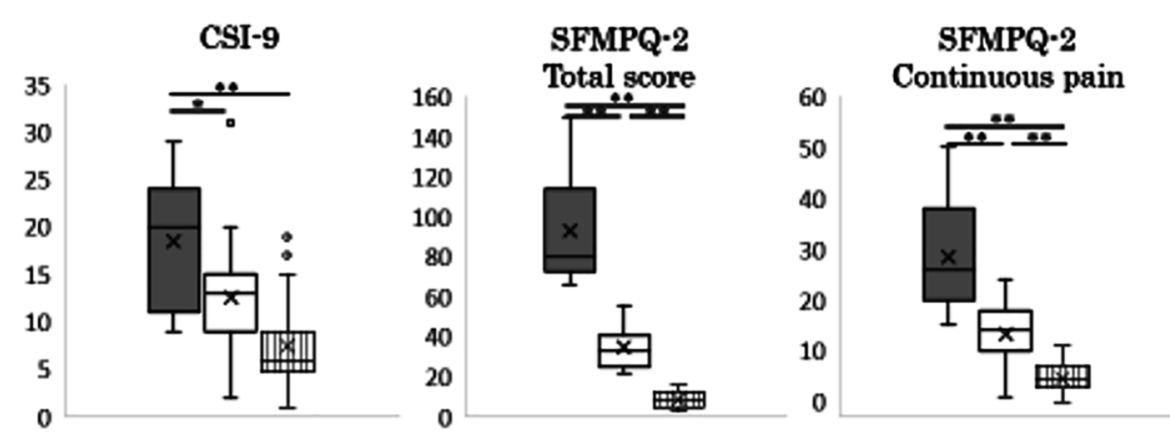

SFMPQ-2

SFMPQ-2

Intermittent pain

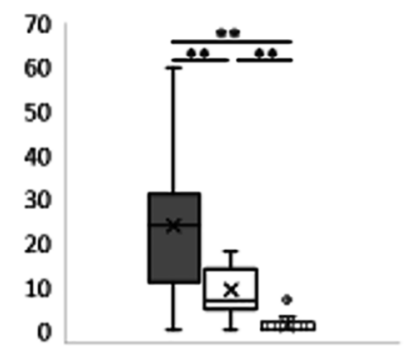

Affective discriptors

SFMPQ-2

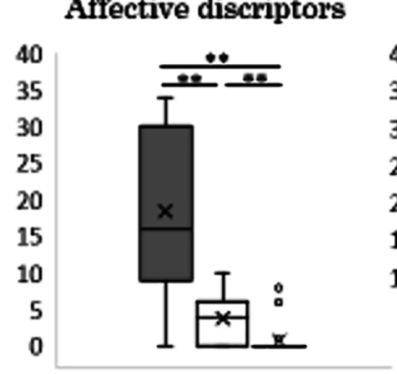

Neuropathic pain
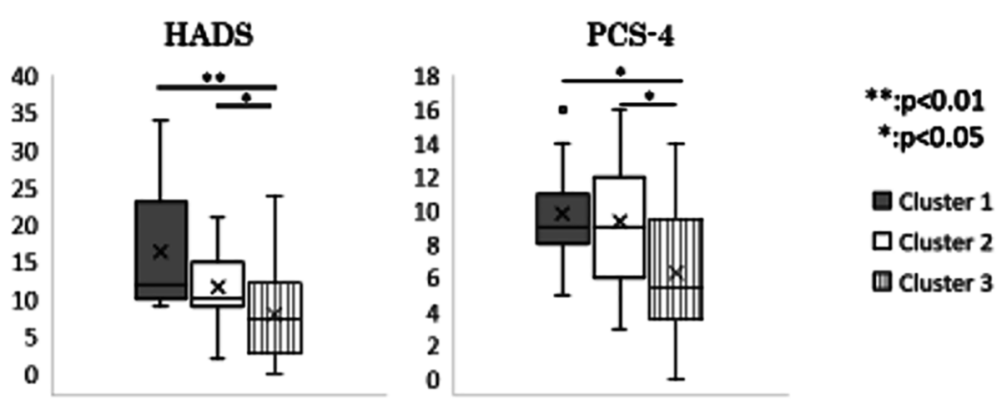

Fig.2 Difference of each variable between clusters.

$P$ value showed the result of multiple comparison (Bonferroni method).

CSI-9, central sensitization inventory-9; SFMPQ-2, Short-Form McGill Pain Questionnaire-2; HADS, hospital anxiety and depression Scale; PCS-4, pain catastrophizing scale- 4 .

ラスター解析の結果，SFMPQ-2 および CSI-9 が高值であるクラスター 1, SFMPQ-2 が中程 度で CSI-9 が低值であるクラスター 2 , SFMPQ-2 および CSI-9 が低值であるクラス ター 3 に分類された。

\section{2. 各クラスター間での基本属性および調査 項目の比較}

各クラスターの基本属性および調查項目の結
果は Table 1 に示す。疼痛部位数については, 各クラスター間で有意差は認められなかったが, 平均值ではクラスター 1 が最も疼痛部位数が大 きかった。疼痛䍜患期間については, 各クラス ター間で有意差は認められなかったが，各クラ スターともに平均で 1 年以上と長期間疼痛を罹 患していた。

SFMPQ-2 は合計值および下位項目ともに全 てのクラスター間で有意差を認めた $(\mathrm{p}<0.01)$ 。 
CSI-9 はクラスター 1 とクラスター $2(\mathrm{p}<0.05)$, クラスター $3(\mathrm{p}<0.01)$ の間で有意差を認めた。 CSI-9 についてはカットオフ基準值に該当する 症例の割合についても算出し, CSI-9のカット オフ基準值である 20 点を満たすものは，クラ スター 1 で 6 名 $(54.5 \%)$, クラスター 2 で 2 名 (10.5\%), クラスター 3 で 2 名 $(6.9 \%)$ であり, クラスター 1 は中枢性感作症候群のカットオフ 基準值からみても, クラスター 2 , クラスター 3 よりも重症度が高い症例の割合が多く認めら れた。HADS はクラスター $1(\mathrm{p}<0.01)$, クラス ター $2(\mathrm{p}<0.05)$ とクラスター 3 の間で有意差を 認めた。PCS はクラスター $1(\mathrm{p}<0.05)$, クラス ター $2(\mathrm{p}<0.05)$ とクラスター 3 の間で有意差を 認めた (Fig.2)。

\section{考察}

中枢性感作症候群と痛みに基づいてサブグ ループ化を行ったところ，3つのサブグループ に分類することが可能であった。全てのクラス ター間の痛みは有意な差があり, 痛みが重度で あるクラスター 1 , 中等度であるクラスター 2 , 軽度であるクラスター 3 に分類された。 SFMPQ-2 の下位項目別で比較したところ, 同 様にすべてのクラスター間で有意な差を認めた ことから, どの痛みの性質においてもクラス ター $1,2,3$ の順に痛みが重度であった。中枢性 感作症候群については, クラスター 1 がクラス ター 2 およびクラスター 3 より高值であり，認 知・情動的因子については, クラスター 1 およ びクラスター 2 がクラスター 3 より高值であっ た。これらのことから, クラスター 1 は痛み, 中枢性感作症候群, 認知・情動的問題の全てが 重度なクラスター, クラスター 2 は痛みと認 知・情動的因子の問題が大きいクラスター, ク
ラスター 3 は痛み, 中枢性感作症候群, 認知・ 情動的因子が軽度なクラスターであったことが わかる。

痛み闇值および認知・情動的因子に基づいた クラスター分析をした先行研究では, 痛み閾值 と認知・情動的因子が中等度のクラスター, 痛 み閾值と認知・情動的因子が重度なクラスター, 痛み閾值は重度だが認知・情動的因子は軽度な クラスターに分類されたと報告されている6)。 本研究においても, 全てのクラスター間の痛み は有意な差があるが，認知・情動的因子ではク ラスター 1 とクラスター 2 の間に有意な差がな いなど, クラスター間によって認知・情動的因 子の影響に違いがあった。加えて, 本研究では 先行研究では検討されていない中枢性感作症候 群の影響についても検討した結果, クラスター 2 とクラスター 3 の痛みは有意な差があるにも かかわらず, 中枢性感作症候群のスコアに有意 差がなかった。このように，クラスター間に よって中枢性感作症候群の影響に違いがあった ことは, 本研究の特徵的な結果であった。つま り,これらのことは, 痛みを増悪させているメ カニズムがクラスターごとによって異なること を示唆する結果である。

痛み増悪の機序として, 中枢性感作, 未梢性 感作, 認知・情動性感作, 対人性感作の影響が 考えられている5)。中枢性感作の影響について は，中枢神経系による痛みの促進および抑制を 表す指標である Temporal Summation (TS) お よび Conditioning Pain Modulation (CPM) を 用いて, 痛みとの関連が報告されている 1)。変 形性股関節症患者の TS と痛みの関連を検討し た先行研究では, TS が高值であれば, 痛みも 重度であり, 人工股関節置換術による痛みの改 善度も乏しかったことから, 痛み増悪に中枢性 感作が影響することが示唆されている8)。加え 
て, 認知・情動的問題が神経活動に影響して痛 みを増悪させると考えられており21，実際に認 知・情動的因子 (不安, 抑うつ, 運動恐怖, 破 局的思考）の重症度の違いにより, 痛みの重症 度も異なることが報告されている4)。本研究に おいて, クラスター 1 とクラスター 2 の中枢性 感作症候群に違いがあったことから, クラス ター 1 の痛みは中枢性感作が影響していること が示唆された。これに加えて, クラスター 1 に は CSI-9 のカットオフ值以上の者が $54.5 \%$ 存在 していたことも, クラスター 1 の痛みが中枢性 感作症候群によるものであることを裏付けてい る。一方で, クラスター 2 とクラスター 3 の認 知・情動的因子に有意な差がみられたことから, クラスター 2 の痛みは認知・情動性感作が直接 的に関与していることが示唆された。また本研 究では, 中枢性感作症候群および認知・情動的 因子がどのような痛みの性質に影響を与えてい るのかについても検討した。先行研究では, SFMPQ-2の下位分類における全ての痛みの性 質で不安および抑うつと正の相関関係を認めて いる20)。本研究においても, 全ての痛みの性質 で全クラスター間に有意な差がみられたことか ら, 中枢性感作症候群および認知・情動的問題 は，痛みの性質の種類にかかわらず悪影響を及 ぼすことが示唆された。

以上のように, 本研究のようなクラスター分 析によって, 痛みを増悪させている因子が対象 者によって異なることが示唆された。今回の結 果は, 疼痛マネジメントにおいて, サブグルー プの特性に応じた個別対応の必要性を示唆する ものであり, 疼痛緩和に対する介入を考える上 で役立つと考えられる。

本研究の限界点としては, 質問紙のみの検討 であり, 中枢神経系の測定は非実施であったた め, 詳細な機序については不明な点が挙げられ
る。また, 横断的調査であるため, 経時的変化 における痛みの増悪・緩和過程は不明である。 そのため, 今後は中枢性感作症候群, 認知・情 動的因子, 痛みの縦断的変化を調査し, 痛みの 増悪・緩和過程における関係性を解明していく ことが必要である。

\section{結語}

中枢性感作症候群によって痛みの重症度が左 右されるグループと, 認知・心理的側面によっ て痛みが影響されるグループが別々に存在し, 痛みが増悪するメカニズムに違いがあることが 明確になった。

\section{文 献}

1) Arendt-Nielsen, L., Skou, S.T., Nielsen, T.A., Petersen, K.K., Altered Central Sensitization and Pain Modulation in the CNS in Chronic Joint Pain, Curr. Osteoporos. Rep., 13(2015) 225-234.

2) Bid, D.D., Soni, C.N., Yadav, S.A., Rathod, V.P., A study on central sensitization in chronic nonspecific low back pain, Indian J. Physiother. Occup. Ther., 11 (2017) 165-175.

3) Bot, A.G.J., Becker, S.J.E., Bruijnzeel, H., Mulders, M.A.M., Ring, D., Vranceanu, A.M., Creation of the abbreviated measures of the Pain Catastrophizing Scale and the Short Health Anxiety Inventory: the PCS-4 and SHAI-5, J. Musculoskelet. Pain, 22 (2014) 145-151.

4) Domenech, J., Sanchis-Alfonso, V., López, L., Espejo, B., Influence of kinesiophobia and catastrophizing on pain and disability in anterior knee pain patients, Knee Surg. Sports Traumatol. Arthrosc., 21 (2013) 1562-1568.

5) English, B., Neural and Psychosocial Mechanisms of Pain Sensitivity in Fibromyalgia, Pain Manag. Nurs., 15 (2014) 530-538.

6) Giesecke, T., Williams, D.A., Harris, R.E., Cupps, T.R., Tian, X., Tian, T.X., Gracely, R.H., Clauw, D.J., Subgrouping of Fibromyalgia Patients on the Basis of Pressure-Pain Thresholds and Psychological Factors, Arthritis Rheum., 48 (2003) 2916-2922. 
7）八田宏之, 東あかね, 八城博子, 小笹晃太郎, 林 恭平, 清田啓介, 井口秀人, 池田順子, 藤田きみ 急, 渡辺能行, 川井啓市, Hospital Anxiety and Depression Scale日本語版の信頼性と妥当性の 検討: 女性を対象とした成績, 心身医学, 38 (1998) 309-315.

8) Izumi, M., Petersen, K.K., Laursen, M.B., ArendtNielsen, L., Graven-Nielsen, T., Facilitated temporal summation of pain correlates with clinical pain intensity after hip arthroplasty, PAIN, 158 (2017) 323-332.

9) Lluch, E., Nijs, J., Courtney, C.A., Rebbeck, T., Wylde, V., Baert, I., Wideman, T.H., Howells, N., Skou, S.T., Clinical descriptors for the recognition of central sensitization pain in patients with knee osteoarthritis, Disabil. Rehabil., 40 (2018) 2836-2845.

10) Loeser, J.D., Treede, R.D., The Kyoto protocol of IASP basic pain Terminology, Pain, 137 (2008) 473-477.

11）圓尾知之, 中江文, 前田倫, 高橋一成田香代子, Morris Shayn, 横江勝, 松崎大河, 柴田政彦, 齊 藤洋一, 痛みの評価尺度・日本語版 ShortForm McGill Pain Questionnaire 2 (SF-MPQ2)の作成とその信頼性と妥当性の検討, PAIN RESERCH, 28 (2013) 43-53.

12) Mayer, T.G., Neblett, R., Cohen, H., Howard, K.J., Choi, Y.H., Williams, M.J., Perez, Y., Gatchel, R.J., The development and psychometric validation of the central sensitization inventory, Pain Pract., 12 (2012) 276-285.

13) Mibu, A., Nishigami, T., Tanaka, K., Manfuku, M., Yono, S., Difference in the impact of central sensitization on pain-related symptoms between patients with chronic low back pain and knee osteoarthritis, J. Pain Res., 12 (2019) 1757-1765.

14) Neblett, R., Hartzell, M.M., Mayer, T.G., Cohen, H., Gatchel, R.J., Establishing clinically relevant severity levels for the central sensitization inventory, Pain Pract., 17 (2017) 166-175.

15) Nishigami, T., Tanaka, K., Mibu, A., Manfuku, M., Yono, S., Tanabe, A., Development and psychometric properties of short form of central sensitization inventory in participants with musculoskeletal pain: A cross-sectional study, PLoS One, 13 (2018) Article ID e0200152.
16) Shigetoh, H., Tanaka, Y., Koga, M., Osumi, M., Morioka, S., The mediating effect of central sensitization on the relation between pain intensity and psychological factors: A cross-sectional study with mediation analysis, Pain Res. Manag., (2019) Article ID 3916135.

17) Tanaka, K., Nishigami, T., Mibu, A., Manfuku, M., Yono, S., Shinohara, Y., Tanabe, A., Ono, R., Validation of the Japanese version of the Central Sensitization Inventory in patients with musculoskeletal disorders, PLoS One, 12 (2017) Article ID e0188719.

18) Tanaka, K., Nishigami T., Mibu, A., Manfuku, M., Yono, S., Yukioka, M., Miki, K., Cutoff value for short form of central sensitization inventory, Pain Pract., 20 (2020) 269-276.

19) Tanaka, K., Murata, S., Nishigami, T., Mibu, A., Manfuku, M., Shinohara, Y., Tanabe, A., Ono, R., The central sensitization inventory predict painrelated disability for musculoskeletal disorders in the primary care setting, Eur. J. Pain, 23 (2019) 1640-1648.

20) Turk, D.C., Dworkin, R.H., Trudeau, J.J., Benson, C., Biondi, D.M., Katz, N.P., Kim, M., Validation of the Hospital Anxiety and Depression Scale (HADS) in Patients with Acute Low Back Pain, J. Pain, 16 (2015) 1012-1021.

21) Ursin, H., Eriksen, H., Cognitive Activation Theory of Stress, Sensitization, and Common Health Complaints, Ann. N. Y. Acad. Sci., 1113 (2007) 304-310.

22) van Wilgen, C.P., Vuijk, P.J., Kregel, J., Voogt, L., Meeus, M., Descheemaeker, F., Keizer, D., Nijs J., Psychological distress and widespread pain contribute to the variance of the central sensitization inventory: a cross-sectional study in patients with chronic pain, Pain Pract., 18 (2018) 239246.

23) Yunus, M.B., Fibromyalgia and overlapping disorders: the unifying concept of central sensitivity syndromes, Semin. Arthritis Rheum., 36 (2007) 339-356.

Address for correspondence: Hayato Shigetoh Department of Neurorehabilitation, Graduate School of Health Sciences, Kio University

4 Chome-2-2 Umaminaka, Koryo, Kitakatsuragi District, Nara Prefecture 635-0832, Japan 